\title{
Desempenho agronômico de cultivares de cevada cervejeira sob diferentes lâminas de irrigação
}

\section{Agronomic performance of barley cultivars under different irrigation depths}

\author{
Fernando Mendes Sanches ${ }^{1}$; Fernando França da Cunha ${ }^{2 *}$ \\ Osvaldir Feliciano dos Santos ${ }^{1}$; Epitácio José de Souza ${ }^{3}$; \\ Aguinaldo José Freitas Leal ${ }^{4}$; Gustavo de Faria Theodoro ${ }^{4}$
}

\section{Resumo}

Objetivou-se avaliar o desempenho agronômico de cultivares de cevada cervejeira submetidas a diferentes lâminas de irrigação no cerrado sul-mato-grossense. O experimento foi conduzido no delineamento inteiramente casualizado, com parcelas subdivididas, tendo nas parcelas quatro lâminas de irrigação $(50,75,100$ e $125 \%$ da evapotranspiração da cultura) e nas subparcelas três cultivares de cevada (BRS Sampa, BRS Manduri e BRS 195), com quatro repetições. As cultivares de cevada diferiram apenas em número de perfilhos por planta, espiguetas por espiga e profundidade do sistema radicular. As produtividades máximas de grãos para as cultivares BRS Sampa, BRS Manduri e BRS 195 foram de 5.848, 5.449 e $4.767 \mathrm{~kg} \mathrm{ha}^{-1}$, respectivamente. A cevada BRS Sampa apresentou valor $17 \%$ superior à produtividade divulgada pelo detentor. As lâminas de irrigação afetaram todas as características agronômicas avaliadas. Recomenda-se para o nordeste sul-mato-grossense a BRS Sampa irrigada com reposição de $100 \%$ da evapotranspiração da cultura, por não ter diferido das demais cultivares e ter sido desenvolvida para região de clima semelhante.

Palavras-chave: BRS Sampa, irrigação por gotejamento, Hordeum vulgare L., produtividade

\begin{abstract}
The research work aimed to evaluate the performance of barley cultivars under different irrigation depths in Brazilian Cerrado. The experiment was conducted in a split plot completely randomized design, with irrigation depths $(50,75,100$ and $125 \%$ of crop evapotranspiration) in the plots and barley cultivars (BRS Sampa, BRS Manduri and BRS 195) in the split-plots, with four replications. Barley cultivars were different regarding number of tillers per plant, number of spikelets per spike, and root depth. The maximum yields for BRS Sampa, BRS Manduri and BRS 195 were 5,848; 5,449; and 4,767 $\mathrm{kg} \mathrm{ha}^{-1}$, respectively. BRS Sampa showed a value $17 \%$ higher than the yield reported by the holder. The irrigation depth affected all the agronomic traits. It is recommended BRS Sampa for Brazilian Cerrado, that didn't differ from other cultivars and was developed in region of similar climate; with replacement of $100 \%$ of crop evapotranspiration.
\end{abstract}

Key words: BRS Sampa, drip irrigation, Hordeum vulgare L., yield

1 Discentes do Curso de Agronomia, Universidade Federal de Mato Grosso do Sul, CPCS/UFMS, Chapadão do Sul, MS. E-mail: fernandomendess92@gmail.com; osvaldir.feliciano@gmail.com

2 Prof. Adjunto, Universidade Federal dos Vales do Jequitinhonha e Mucuri, ICA/UFVJM, Unaí, MG. E-mail: fernando.cunha@, ufvjm.edu.br

3 Discente do Curso de Doutorado em Agronomia, Universidade Estadual Paulista "Júlio de Mesquita Filho", UNESP, Ilha Solteira, SP. E-mail: epitacio_jose@hotmail.com

4 Profs. Adjuntos, CPCS/UFMS, Chapadão do Sul, MS. E-mail: aguinaldo.leal@ufms.br; gustavo.theodoro@ufms.br

* Autor para correspondência 


\section{Introdução}

Ocupando a quarta posição em ordem de área plantada no mundo, a cevada (Hordeum vulgare L.) é um cereal utilizado principalmente na produção de bebidas e alimentação animal, estando também presente na composição de farinhas ou flocos para panificação, na produção de medicamentos e na formulação de produtos dietéticos e de sucedâneos de café (YALÇIN et al., 2007).

O Estado de Mato Grosso do Sul se destaca na produção de grãos, fibra e pecuária de corte, apresentando poucas iniciativas no cultivo de cevada. Entretanto, do ponto de vista agrícola, a cevada é uma alternativa para rotação de culturas como o feijão, e tem mostrado eficiência, pois não é hospedeira de doenças como o mofo branco, a fusariose e a rhizoctoniose, além de ser uma espécie adaptada às condições climáticas de inverno (AMABILE et al., 2008), características que qualifica essa cultura como alternativa para rotação também com a cultura da soja. O cultivo de cevada cervejeira torna-se assim uma alternativa viável tanto do ponto de vista técnico econômico, quanto do ponto de vista ecológico.

A literatura existente sobre o desempenho agronômico e econômico de cevada na região de cerrado Sul-Mato-Grossense ainda é escassa. Portanto, há a necessidade de estudar a adaptação de cultivares ao clima da região, considerando a adaptação da cultivar ao solo da região, a suscetibilidade às pragas e doenças causadas por fungos, bactérias, vírus e nematóides e aos distúrbios fisiológicos.

Além da escolha da variedade adequada, a utilização de sistemas de irrigação para suprir de forma total ou suplementar as necessidades hídricas da cevada é importante para altas produtividades. No Brasil, a agricultura irrigada é a maior consumidora de água, dentre as diversas atividades humanas. $\mathrm{Na}$ maioria das áreas irrigadas, a ausência de manejo racional da água resulta em aplicação excessiva, com desperdício de água e energia. Práticas adequadas de irrigação contribuem para aumentar a produtividade das culturas, melhorar a qualidade dos produtos agrícolas, minimizar o uso da água e preservar os recursos hídricos. Diante disso, o controle da irrigação e pesquisas para determinação de lâmina ótima de irrigação pode contribuir para a produção de cevada.

A presente pesquisa buscou avaliar a potencialidade da produção deste cereal em Mato Grosso do Sul, buscando assim obter uma nova alternativa de rotação de culturas no inverno. O objetivo específico foi avaliar o efeito de diferentes lâminas de irrigação por gotejamento no desempenho agronômico de três cultivares de cevada cervejeira.

\section{Material e Métodos}

O experimento foi conduzido na área experimental do Campus da Universidade Federal de Mato Grosso do Sul situado em Chapadão do Sul-MS, com latitude de $18^{\circ} 48^{\prime} 459^{\prime \prime}$ Sul, longitude $52^{\circ} 36^{\prime} 003$ " Oeste e altitude de 820 metros. O clima é classificado como tropical úmido, a temperatura anual fica compreendida entre 13 a $28{ }^{\circ} \mathrm{C}$, a precipitação pluviométrica média é de $1.850 \mathrm{~mm}$, com concentração de chuva no verão e seca no inverno (PREFEITURA MUNICIPAL CHAPADÃO DO SUL, 2012).

O solo foi classificado como Latossolo Vermelho distrófico de textura argilosa com baixa fertilidade natural, com horizonte B latossólico, o qual foi originalmente ocupado por vegetação de cerrado e cultivado por culturas anuais há vários anos sob manejo convencional, sendo que a última cultura explorada no verão foi o rabanete.

$\mathrm{Na}$ análise química do solo obtiveram-se os seguintes resultados: $13,8 \mathrm{mg} \mathrm{dm}^{-3}$ de $\mathrm{P}$ (resina); 40,2 $\mathrm{g} \mathrm{dm}^{-3}$ de M.O.; 5,3 de $\mathrm{pH}\left(\mathrm{CaCl}_{2}\right) ; \mathrm{K}^{+}, \mathrm{Ca}^{2+}$, $\mathrm{Mg}^{+2}$ e $\mathrm{H}+\mathrm{Al}=2,9 ; 33,3 ; 9,0$ e 49,0 $\mathrm{mmol}_{\mathrm{c}} \mathrm{dm}^{-3}$, respectivamente, e $47,8 \%$ de saturação por bases. O preparo do solo foi efetuado por meio de uma aração e gradagem no início de maio de 2012. A calagem e 
adubação foi realizada de forma manual de acordo com as necessidades da cultura e baseado na análise química do solo (MINELLA, 2012).

Quanto às análises físico-hídricas, os teores de água no solo equivalente a capacidade de campo e ao ponto de murcha permanente da planta foram obtidos por meio das curvas de retenção de água no solo usando-se o extrator de Richards (RICHARDS, 1949). Os teores de água equivalentes a capacidade de campo para as camadas 0-20 e 20-40 cm foram de 0,2662 e $0,2602 \mathrm{~m}^{3} \mathrm{~m}^{-3}$, respectivamente. Os teores de água equivalentes ao ponto de murcha para as camadas de 0-20 e 20-40 cm foram de 0,1878 e $0,1895 \mathrm{~m}^{3} \mathrm{~m}^{-3}$, respectivamente. A densidade do solo foi determinada pelo método do anel volumétrico, encontrando valores de 1,2208 e $1,1954 \mathrm{~g} \mathrm{dm}^{-3}$ para as camadas $0-20$ e $20-40 \mathrm{~cm}$ de profundidade, respectivamente.

O experimento foi realizado entre 20 de maio a 28 de agosto de 2012 e conduzido em esquema de parcelas subdivididas, tendo nas parcelas quatro lâminas de irrigação (50, 75, 100 e 125\% da evapotranspiração da cultura) e nas subparcelas três cultivares de cevada (BRS Sampa, BRS Manduri e BRS 195), no delineamento inteiramente casualizado, com quatro repetições. As parcelas foram constituídas por 6 linhas de plantas, com 12 $\mathrm{m}$ de comprimento, com espaçamento duplo de $17 \mathrm{x}$ $34 \mathrm{~cm}$, apresentando área de 18,36 $\mathrm{m}^{2}$.

A semeadura foi realizada em sulcos no dia 20 de março de 2012. A semente foi depositada uniformemente no solo, em profundidade entre 3 e $5 \mathrm{~cm}$. Para o controle de plantas invasoras foi realizado capina manual nas entrelinhas de plantio. O manejo fitossanitário para controle de pragas e doenças foi realizado de acordo com as necessidades da cultura, conforme segue:

1 - Tratamento de sementes: Tiofanato Metílico (63 g por $100 \mathrm{~kg}$ de sementes) e Acetamiprido (210 g por $100 \mathrm{~kg}$ de sementes $)$ - (20/05/2012)

2 - Primeira aplicação: Tiametoxan+Lambdacialotrina $\left(21+15 \mathrm{~mL} \mathrm{ha}^{-1}\right)$ e Epoxiconazol $(183 \mathrm{~mL}$ ha $\left.^{-1}\right)-(29 / 06 / 2012)$

3 - Segunda aplicação: Tiametoxan+Lambdacialotrina $\left(21+15 \mathrm{~mL} \mathrm{ha}^{-1}\right)$ e Epoxiconazol $(183 \mathrm{~mL}$ $\left.\mathrm{ha}^{-1}\right)-(06 / 08 / 2012)$

4 - Terceira aplicação: Epoxiconazol (183 mL ha $\left.^{-1}\right)-(02 / 09 / 2012)$

Houve a diagnose e a anotação da incidência (\%) de doenças que foram encontradas nas plantas durante a condução do experimento. $\mathrm{O}$ fornecimento de água foi realizado por meio de um sistema de gotejamento fixo, com turno de rega de 3 dias. O sistema de irrigação foi constituído de um reservatório de 20 metros de altura, uma adutora de PVC de $50 \mathrm{~mm}$ de diâmetro, tubulação principal de PVC de $32 \mathrm{~mm}$ de diâmetro e linhas laterais de gotejadores (mangueira gotejadora Petroisa) com 16 $\mathrm{mm}$ de diâmetro interno, vazão de $1,58 \mathrm{~L} \mathrm{~h}^{-1} \mathrm{e}$ com espaçamento de $0,2 \mathrm{~m}$ entre emissores. Foi adotada uma linha lateral para cada fileira dupla de planta.

A irrigação real necessária foi determinada em função de parâmetros das características do clima, planta e solo (Eq. 1), que representa a real necessidade de água do sistema.

$$
I T N_{L O C}=\frac{\sum_{d i a 1}^{i} E T_{O} K_{C} K_{S} K_{L}}{E_{A}}-P_{E}
$$

Onde:

ITN $_{\text {LOC }}$ : irrigação total necessária em sistemas localizados (mm);

$\mathrm{ET}_{0}$ : evapotranspiração de referência $\left(\mathrm{mm} \mathrm{dia}^{-1}\right)$;

$\mathrm{K}_{\mathrm{C}}$ : coeficiente da cultura (adimensional);

$\mathrm{K}_{\mathrm{S}}$ : coeficiente de umidade do solo (adimensional);

$\mathrm{K}_{\mathrm{L}}$ : coeficiente de localização (adimensional);

$\mathrm{E}_{\mathrm{A}}$ : eficiência de aplicação da água de irrigação (decimal);

$\mathrm{P}_{\mathrm{E}}$ : precipitação efetiva no período $(\mathrm{mm})$. 
Os dados meteorológicos diários utilizados no cálculo da evapotranspiração de referência foram retirados do INMET (Instituto Nacional de Meteorologia) rede de estação de Chapadão do Sul. A equação utilizada para estimar a evapotranspiração de referência foi a de Penman-Monteith (Eq. 2). A precipitação pluviométrica foi obtida por meio de um pluviômetro instalado na área experimental.

$$
E T_{0}=\frac{0,408 s\left(R_{N}-G\right)+\gamma \frac{900}{t+273} U_{2} \frac{\left(e_{S}-e\right)}{10}}{s+\gamma\left(1+0,34 U_{2}\right)}
$$

Onde:

$\mathrm{ET}_{0}$ : evapotranspiração de referência $\left(\mathrm{mm} \mathrm{dia}^{-1}\right)$;

$\mathrm{s}$ : declividade da curva de pressão de saturação $(\mathrm{kPa}$ $\left.{ }^{\circ} \mathrm{C}^{-1}\right)$;

$\mathrm{R}_{\mathrm{N}}$ : saldo de radiação $\left(\mathrm{MJ} \mathrm{m}^{-2}\right.$ dia $\left.^{-1}\right)$;

$\mathrm{G}$ : fluxo de calor no solo $\left(\mathrm{MJ} \mathrm{m}^{-2} \mathrm{dia}^{-1}\right)$;

$\gamma$ : constante psicrométrica $\left(\mathrm{kPa}^{\circ} \mathrm{C}^{-1}\right)$;

t: temperatura média do ar $\left({ }^{\circ} \mathrm{C}\right)$;

$\mathrm{U}_{2}$ : velocidade do vento $\left(\mathrm{m} \mathrm{s}^{-1}\right)$;

$\mathrm{e}_{\mathrm{S}}$ : pressão de saturação de vapor d'água $(\mathrm{hPa})$;

e: pressão atual de vapor d'água (hPa).

O coeficiente de cultivo $\left(\mathrm{K}_{\mathrm{C}}\right)$ foi utilizado segundo recomendações de Guerra e Rocha (2004). Os coeficientes de umidade do solo $\left(\mathrm{K}_{\mathrm{S}}\right)$ e de localização $\left(\mathrm{K}_{\mathrm{L}}\right)$ foram de acordo com as Equações 3 e 4 , respectivamente.

$$
\begin{gathered}
K_{S}=\frac{\operatorname{Ln}(L A A+1)}{\operatorname{Ln}(C T A+1)} \\
K_{L}=0,1 \sqrt{P}
\end{gathered}
$$

Onde:

$\mathrm{K}_{\mathrm{S}}$ : coeficiente de umidade do solo (adimensional);

LAA: lâmina atual de água no solo (mm);
CTA: capacidade total de água no solo (mm);

$\mathrm{K}_{\mathrm{L}}$ : coeficiente de localização (adimensional);

P: maior valor entre porcentagem de área molhada ou sombreada (\%).

A eficiência de aplicação da água foi estimada rotineiramente considerando o coeficiente de uniformidade de distribuição de água (Eq. 5). Para isso, foi utilizada a metodologia proposta por Keller e Karmeli (1975), modificada por Denículi et al. (1980), que consiste na estimativa das vazões de 8 emissores ao longo da mangueira gotejadora em 4 linhas do setor.

$$
C U D=\frac{q_{\mathfrak{z}}}{q_{m}}
$$

Onde:

CUD: coeficiente de uniformidade de distribuição $(\%)$;

$\mathrm{q}_{25}$ : média do menor quartil das vazões $\left(\mathrm{L} \mathrm{h}^{-1}\right)$;

$\mathrm{q}_{\mathrm{m}}$ : média das vazões $\left(\mathrm{L} \mathrm{h}^{-1}\right)$.

Para aferição do manejo da irrigação por evapotranspiração, a umidade atual foi acompanhada por meio do potencial matricial de água no solo feito por tensiômetros digitais instalados a 20 e 40 $\mathrm{cm}$ de profundidade nos tratamentos com lâmina de irrigação de $100 \%$ da ETc.

A colheita da primeira cultivar (BRS Manduri) de cevada foi realizada em 5 de setembro de 2012, e a segunda e terceira cultivares foram colhidas em 17 de setembro de 2012, quando $70 \%$ das plantas apresentavam a folha do ápice (folha bandeira) com coloração típica de maturação, sendo descartadas as duas linhas de bordadura.

O material colhido foi submetido à trilha, pesagem e secagem em estufa com circulação forçada de ar a $65^{\circ} \mathrm{C}$, por um período de 72 horas, após isso sendo pesado novamente. Foram avaliados: a) altura das plantas na maturação, definida como sendo à distância do nível do solo até a extremidade superior 
das espigas, excluindo-se as aristas, medindo-se oito plantas por repetição; b) matéria seca da parte aérea por meio da coleta ao acaso de oito plantas; c) contagem do número de perfilhos por planta por meio da coleta de oito plantas por repetição selecionadas ao acaso; d) contagem do número de perfilhos viáveis por metro; e) contagem do número de perfilhos inviáveis por metro; f) comprimento de espiga, determinado em oito espigas, por repetição, definida como sendo a distância do início da ráquis até a extremidade da espiga, excluindo-se as aristas; g) número de espiguetas por espiga por meio da coleta de oito espigas; $h$ ) número de grãos por espiga; i) produtividade de grãos, determinada pela coleta dos grãos das plantas contidas nas 4 linhas centrais de cada repetição, e correção da umidade dos mesmos a $13 \%$; j) peso de 1.000 grãos, determinada em balança de precisão 0,01 $\mathrm{g} ; \mathrm{k})$ profundidade do sistema radicular obtida por meio da abertura de uma trincheira transversal por repetição, atingindo as duas linhas centrais; 1) eficiência do uso da água determinada pela razão entre a produtividade e quantidade de água utilizada no ciclo da cultura (Eq. 6), seguindo recomendações de Pieterse, Rethman; Van Boch (1997).

$$
\mathrm{EUA}=\frac{\mathrm{P}}{\mathrm{L}}
$$

Onde:

EUA: eficiência do uso da água $\left(\mathrm{kg} \mathrm{m}^{-3}\right)$;

P: produtividade de grãos de cevada $\left(\mathrm{kg} \mathrm{ha}^{-1}\right)$;

L: lâmina de água utilizada no período de produção $\left(\mathrm{m}^{3} \mathrm{ha}^{-1}\right)$.
Para a realização da análise estatística, os dados foram submetidos às análises de variância e de regressão. A comparação de médias foi realizada usando-se o teste de Tukey a 5\% de probabilidade. Para o fator quantitativo, os modelos foram escolhidos com base na significância dos coeficientes de regressão, utilizando-se o teste $\mathrm{t}$ a $10 \%$ de probabilidade, no coeficiente de determinação $\left(\mathrm{R}^{2}\right)$ e no fenômeno biológico. Para execução das análises estatísticas, foram utilizados os programas estatísticos Assistat 7.6 e SigmaPlot 11.0. Independente da interação entre os fatores serem ou não significativo, optou-se pelo desdobramento da mesma, devido ao interesse da pesquisa.

\section{Resultados e Discussão}

Os valores médios de temperatura do ar apresentaram grandes oscilações durante todo o período experimental e variaram de 12,2 a $24,1{ }^{\circ} \mathrm{C}$ (Figura 1A). A umidade relativa ficou compreendida entre 32,8 e 97,1\% (Figura 1A). Os valores médios diários de evapotranspiração de referência $\left(\mathrm{ET}_{0}\right)$ durante o período experimental variaram de 1,35 a 4,86 $\mathrm{mm} \mathrm{dia}^{-1}$ e observa-se um aumento no final desse período (Figura 1B). Houve onze precipitações pluviais em todo o período experimental, totalizando uma altura de $128,9 \mathrm{~mm}$ de chuva (Figura 1B). Alturas inferiores a $1 \mathrm{~mm}$ não foram consideradas precipitações (COSTA, 1994). 
Figura 1. Valores diários médios de $(\mathrm{A})$ valores médios, mínimos e máximos diários de temperatura $\left({ }^{\circ} \mathrm{C}\right)$, umidade relativa (\%), (B) precipitação pluvial (mm) e evapotranspiração de referência (mm), durante o período experimental. Chapadão do Sul-MS, 2012.

A

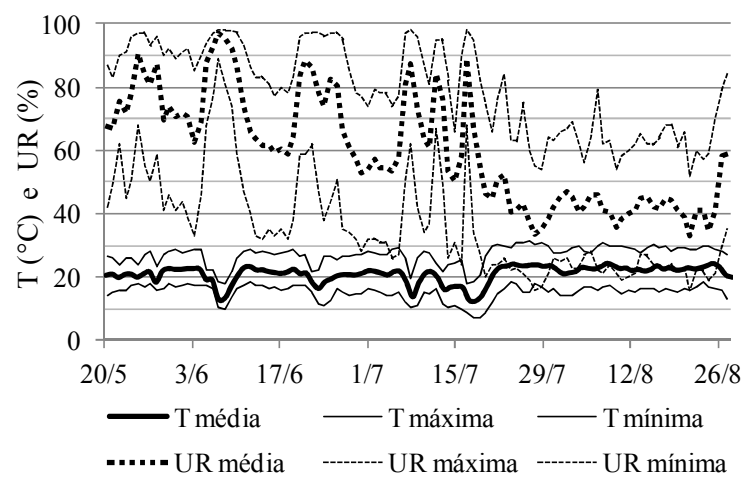

Fonte: Elaboração dos autores.

No geral, observou-se efeito isolado e/ou interação das lâminas de irrigação e distintas cultivares nas características avaliadas da cevada cervejeira (Tabela 1). Não foi verificada diferença significativa entre as alturas de planta nas diferentes cultivares de cevada. Esse resultado era esperado devido ao porte anão dos cultivares como classificado pela EMBRAPA (2013). Mollah e Paul (2011) avaliando diferentes acessos de cevada cervejeira em Bangladesh verificaram diferença de altura entre as cultivares, justificandose pela variabilidade genética entre os materiais. No presente trabalho essa variabilidade não existe uma vez que a cultivar BRS Manduri é originária do cruzamento da BRS 195. Já as lâminas de irrigação proporcionaram efeito quadrático na altura de planta das cultivares de cevada (Figura 2) corroborando com Mollah e Paul (2011) e Rahman et al. (2001). As alturas máximas, estimadas pela equação de regressão, para as cultivares BRS Sampa, BRS Manduri e BRS 195 foram de 64,4; 68,0 e 68,3 cm, para as lâminas de irrigação de 113,7; 120,8 e $118,4 \%$ da ETc, respectivamente. Monteiro (2012) e Borowski (2012) encontraram alturas de planta de 66 e $69 \mathrm{~cm}$ para a cevada BRS 195, em PlanaltinaDF e Passo Fundo-RS, respectivamente. Mollah e

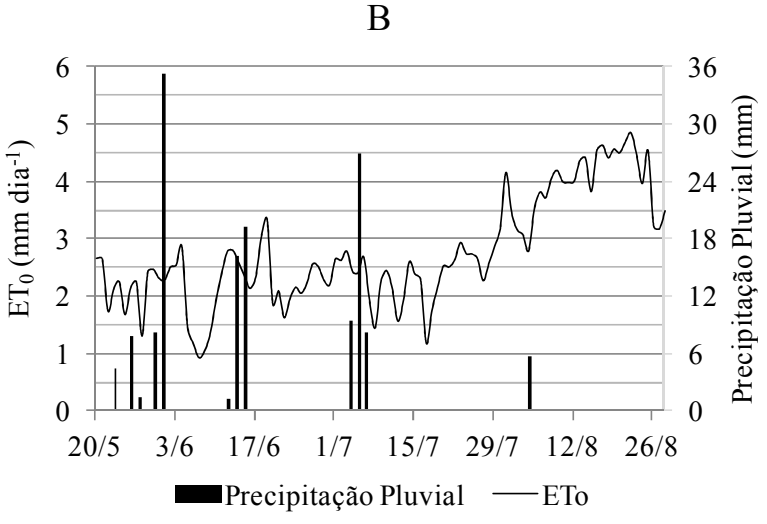

Paul (2011) e Guerra (1994) avaliando diferentes cultivares de cevada em Bangladesh e PlanaltinaDF, também encontraram maiores alturas de planta nos tratamentos que não receberam estresse hídrico.

A matéria seca da parte aérea não foi afetada pelas diferentes cultivares de cevada (Tabela 1). As lâminas de irrigação proporcionaram efeito linear positivo na matéria seca da parte aérea da cevada BRS Manduri, ou seja, o aumento da lâmina de irrigação proporcionou aumento dessa variável. Araya et al. (2010) avaliando a cevada na Etiópia também observaram aumento da biomassa com lâminas crescentes de irrigação. Nas outras cultivares, a lâmina de irrigação proporcionou efeito quadrático (Figura 2). Os valores máximos de matéria seca da parte aérea, estimados pelas equações de regressão, para as cultivares BRS Sampa e BRS 195, foram de 73,31 e $80,61 \mathrm{Mg} \mathrm{ha}^{-1}$, para as lâminas de irrigação de 112,2 e $100,5 \%$ da ETc, respectivamente.

Verifica-se nos diferentes tratamentos que a cevada apresentou variação entre 2,03 e 3,69 perfilhos por planta (Tabela 2). Esses valores são próximos aos encontrados na literatura (GUERRA, 1994; MOLLAH; PAUL, 2011; BOROWSKI, 2012). A cultivar BRS Manduri apresentou menor número de perfilhos por planta nos tratamentos com 
maior lâmina de irrigação. No tratamento de $125 \%$ da ETc, a cultivar BRS Sampa apresentou o maior número de perfilhos por planta. A BRS Sampa é a primeira cultivar desenvolvida para o Estado de São Paulo, que apresenta clima semelhante ao do local onde foi realizado a presente pesquisa.
Independente da cultivar de cevada, a lâmina de irrigação proporcionou efeito linear positivo no número de perfilhos por planta (Figura 2), ou seja, o aumento da lâmina de irrigação proporcionou aumento nessa variável. Esse resultado corrobora com os obtidos por Mollah e Paul (2011).

Tabela 1. Análise de variância de altura de planta $(\mathrm{cm})$, matéria seca da parte aérea $\left(\mathrm{Mg} \mathrm{ha}^{-1}\right)$, perfilhos por planta, perfilhos viáveis por metro, perfilhos inviáveis por metro, comprimento de espiga $(\mathrm{cm})$, espiguetas por espiga, grãos por espiga, peso de 1.000 grãos $(\mathrm{g})$, produtividade de grãos $\left(\mathrm{Mg} \mathrm{ha}^{-1}\right)$, profundidade do sistema radicular $(\mathrm{cm}) \mathrm{e}$ eficiência do uso da água $\left(\mathrm{kg} \mathrm{m}^{-3}\right)$. Chapadão do Sul-MS, 2012.

\begin{tabular}{|c|c|c|c|c|c|c|c|}
\hline \multirow{2}{*}{$\begin{array}{l}\text { Fonte de } \\
\text { Variação }\end{array}$} & \multirow{2}{*}{$\begin{array}{l}\text { Graus de } \\
\text { Liberdade }\end{array}$} & \multicolumn{6}{|c|}{ Quadrado Médio } \\
\hline & & $\begin{array}{l}\text { Altura de } \\
\text { Planta }\end{array}$ & $\begin{array}{l}\text { Mat. Seca } \\
\text { da P. Aérea }\end{array}$ & $\begin{array}{l}\text { Perf. por } \\
\text { Planta }\end{array}$ & $\begin{array}{l}\text { Perf. Viáveis } \\
\text { por Metro }\end{array}$ & $\begin{array}{l}\text { Perf. Inv. } \\
\text { por Metro }\end{array}$ & $\begin{array}{l}\text { Comp. de } \\
\text { Espiga }\end{array}$ \\
\hline LI & 3 & $8,01 \mathrm{E}+2^{* *}$ & $1,11 \mathrm{E}+3^{* *}$ & $3,40 \mathrm{E}+0^{* *}$ & $8,55 \mathrm{E}+3^{*}$ & $1,05 \mathrm{E}+2^{\mathrm{ns}}$ & $2,22 \mathrm{E}+0^{*}$ \\
\hline Resíd & 12 & $2,85 \mathrm{E}+1$ & $1,78 \mathrm{E}+2$ & $7,40 \mathrm{E}-2$ & $1,62 \mathrm{E}+3$ & $1,37 \mathrm{E}+2$ & $5,57 \mathrm{E}-1$ \\
\hline $\mathrm{CC}$ & 2 & $4,54 \mathrm{E}+1^{\mathrm{ns}}$ & $2,42 \mathrm{E}+2^{\mathrm{ns}}$ & $4,81 \mathrm{E}-1^{*}$ & $4,93 \mathrm{E}+1^{\mathrm{ns}}$ & $2,61 \mathrm{E}+1^{\mathrm{ns}}$ & $7,66 \mathrm{E}-1^{\mathrm{ns}}$ \\
\hline LI $x$ CC & 6 & $6,83 \mathrm{E}+0^{\mathrm{ns}}$ & $2,26 \mathrm{E}+2^{\mathrm{ns}}$ & $3,91 \mathrm{E}-1^{* *}$ & $2,96 \mathrm{E}+2^{\mathrm{ns}}$ & $4,46 \mathrm{E}+1^{\mathrm{ns}}$ & $2,67 \mathrm{E}-1^{\mathrm{ns}}$ \\
\hline Resíduo B & 24 & $3,48 \mathrm{E}+1$ & $1,47 \mathrm{E}+2$ & $1,03 \mathrm{E}-1$ & $6,04 \mathrm{E}+2$ & $1,47 \mathrm{E}+2$ & $5,18 \mathrm{E}-1$ \\
\hline Total & 47 & $2,44 \mathrm{E}+4$ & $2,44 \mathrm{E}+4$ & $2,44 \mathrm{E}+4$ & $2,44 \mathrm{E}+4$ & $2,44 \mathrm{E}+4$ & $2,44 \mathrm{E}+4$ \\
\hline \multirow{2}{*}{\multicolumn{2}{|c|}{$\begin{array}{l}\text { CV(\%) Parcela } \\
\text { CV(\%) Subparcela }\end{array}$}} & 8,84 & 19,32 & 10,34 & 40,55 & 39,69 & 9,60 \\
\hline & & 9,78 & 17,53 & 12,18 & 24,78 & 41,13 & 9,26 \\
\hline \multirow{2}{*}{$\begin{array}{l}\text { Fonte de } \\
\text { Variação }\end{array}$} & \multirow{2}{*}{$\begin{array}{l}\text { Graus de } \\
\text { Liberdade }\end{array}$} & \multicolumn{6}{|c|}{ Quadrado Médio } \\
\hline & & $\begin{array}{l}\text { Espiguetas } \\
\text { por Espiga }\end{array}$ & $\begin{array}{l}\text { Grãos por } \\
\text { Espiga }\end{array}$ & $\begin{array}{c}\text { Peso de } \\
1.000 \text { Grãos }\end{array}$ & $\begin{array}{l}\text { Prod. de } \\
\text { Grãos }\end{array}$ & $\begin{array}{l}\text { Prof. Sist. } \\
\text { Radicular }\end{array}$ & $\begin{array}{l}\text { Ef. do Uso } \\
\text { da Água }\end{array}$ \\
\hline LI & 3 & $1,67 \mathrm{E}+0^{\text {ns }}$ & $5,05 \mathrm{E}+2^{* *}$ & $5,26 \mathrm{E}+1^{*}$ & $4,27 \mathrm{E}+1^{* *}$ & $1,03 \mathrm{E}+2^{* *}$ & $4,63 \mathrm{E}+0^{* *}$ \\
\hline Resíduo A & 12 & $5,41 \mathrm{E}-1$ & $1,05 \mathrm{E}+1$ & $1,24 \mathrm{E}+1$ & $5,96 \mathrm{E}-1$ & $5,42 \mathrm{E}+0$ & $1,27 \mathrm{E}-1$ \\
\hline $\mathrm{CC}$ & 2 & $1,35 \mathrm{E}+1^{* *}$ & $1,18 \mathrm{E}+1^{\mathrm{ns}}$ & $1,71 \mathrm{E}+1^{\mathrm{ns}}$ & $1,15 \mathrm{E}-1^{\mathrm{ns}}$ & $3,24 \mathrm{E}+0^{\mathrm{ns}}$ & $5,04 \mathrm{E}-2^{\mathrm{ns}}$ \\
\hline $\mathrm{LI} \times \mathrm{CC}$ & 6 & $5,39 \mathrm{E}-1^{\mathrm{ns}}$ & $1,15 \mathrm{E}+1^{\mathrm{ns}}$ & $5,89 \mathrm{E}+0^{\text {ns }}$ & $1,27 \mathrm{E}+0^{\mathrm{ns}}$ & $1,70 \mathrm{E}+1^{*}$ & $3,11 \mathrm{E}-1^{\mathrm{ns}}$ \\
\hline Resíduo B & 24 & $6,96 \mathrm{E}-1$ & $7,42 \mathrm{E}+0$ & $5,20 \mathrm{E}+0$ & $6,20 \mathrm{E}-1$ & $4,86 \mathrm{E}+0$ & $1,42 \mathrm{E}-1$ \\
\hline Total & 47 & $2,44 \mathrm{E}+4$ & $2,44 \mathrm{E}+4$ & $2,44 \mathrm{E}+4$ & $2,44 \mathrm{E}+4$ & $2,44 \mathrm{E}+4$ & $2,44 \mathrm{E}+4$ \\
\hline \multicolumn{2}{|c|}{ CV(\%) Parcela } & 5,66 & 12,36 & 8,52 & 18,63 & 7,33 & 20,40 \\
\hline \multicolumn{2}{|c|}{ CV(\%) Subparcela } & 6,42 & 10,40 & 5,51 & 19,00 & 6,94 & 21,56 \\
\hline
\end{tabular}

LI - lâmina de irrigação; CC - cultivar de cevada; ${ }^{*} p<0,05 ;{ }^{* *} p<0,01 ;{ }^{\text {ns }} p>0,05$.

Fonte: Elaboração dos autores. 
Figura 2. Estimativa de altura de planta (AP), matéria seca da parte aérea (MSA), perfilhos por planta (PP), perfilhos viáveis por metro (PVM), perfilhos inviáveis por metro (PIM), comprimento de espiga (CE), espiguetas por espiga (EE), grãos por espiga (GE), peso de 1.000 grãos $(\mathrm{PMG})$, produtividade de grãos $(\mathrm{P})$, profundidade do sistema radicular (PSR) e eficiência do uso da água (EUA) submetida a diferentes lâminas de irrigação (LI), para diferentes cultivares de cevada. Chapadão do Sul-MS, 2012.

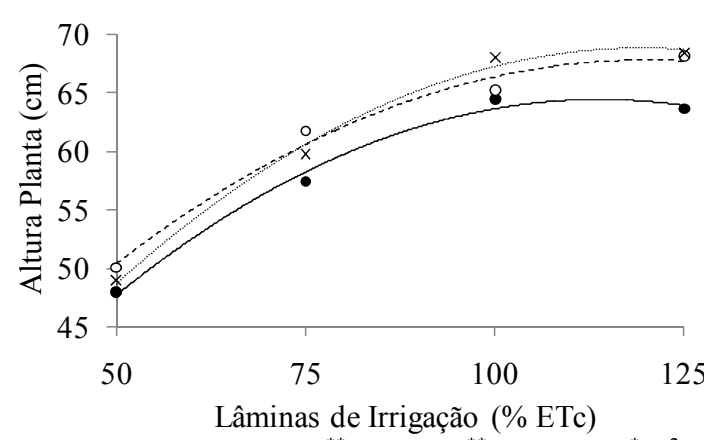

Sampa: AP $=11,3695^{* *}+0,9321^{* *} \mathrm{LI}-0,0041^{*} \mathrm{LI}^{2}$ $p<0,0001 \quad \mathrm{R}^{2}=0,9912$

Manduri: $\mathrm{AP}=16,9609^{*}+0,8453^{* * *} \mathrm{LI}-0,0035^{*} \mathrm{LI}^{2}$ $p=0,0049 \quad \mathrm{R}^{2}=0,9844$

195: $\mathrm{AP}=9,4172^{*}+0,9946^{* *} \mathrm{LI}-0,0042^{* *} \mathrm{LI}^{2}$ $p=0,0004 \quad \mathrm{R}^{2}=0,9945$

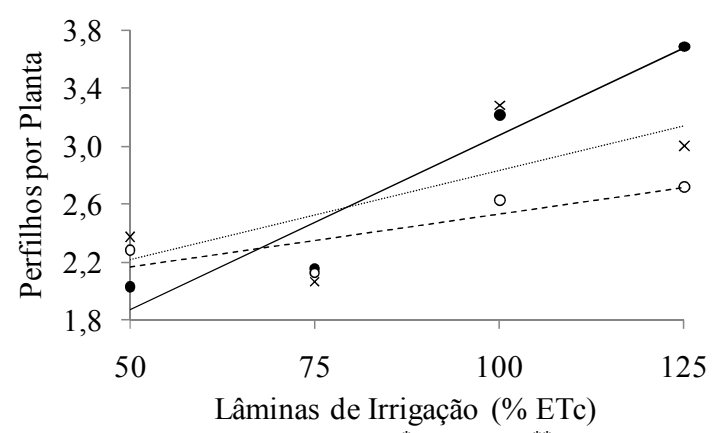

Sampa: $\mathrm{PP}=0,6625^{*}+0,0241^{* *} \mathrm{LI}$

$p<0,0001 \quad \mathrm{r}^{2}=0,9253$

Manduri: $\mathrm{PP}=1,8031^{*}+0,0073^{* *} \mathrm{LI}$

$p=0,0126 \quad \mathrm{r}^{2}=0,6950$

195: $\mathrm{PP}=1,5969^{* *}+0,0124^{*} \mathrm{LI}$

$p=0,0122 \quad \mathrm{r}^{2}=0,5101$

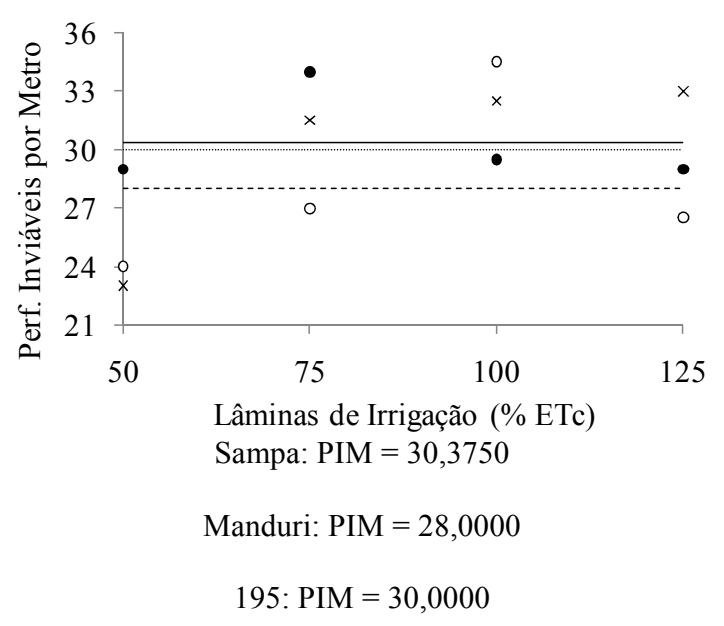

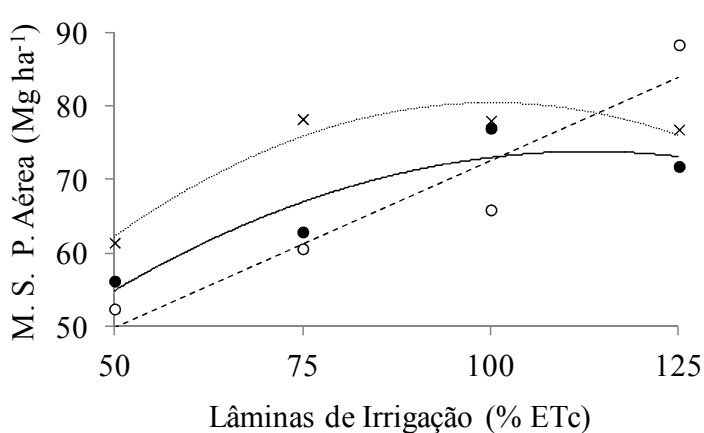

Sampa: MSA $=12,9088^{*}+1,0769^{* *} \mathrm{LI}-0,0048^{*} \mathrm{LI}^{2}$ $p=0,0064 \quad \mathrm{R}^{2}=0,8608$

Manduri: MSA $=27,1865^{* *}+0,4529^{* *} \mathrm{LI}$ $p=0,0046 \quad \mathrm{r}^{2}=0,9001$

195: $\mathrm{MSA}=7,9226^{*}+1,4469^{* *} \mathrm{LI}-0,0072^{*} \mathrm{LI}^{2}$

$p=0,0153 \quad \mathrm{R}^{2}=0,9355$

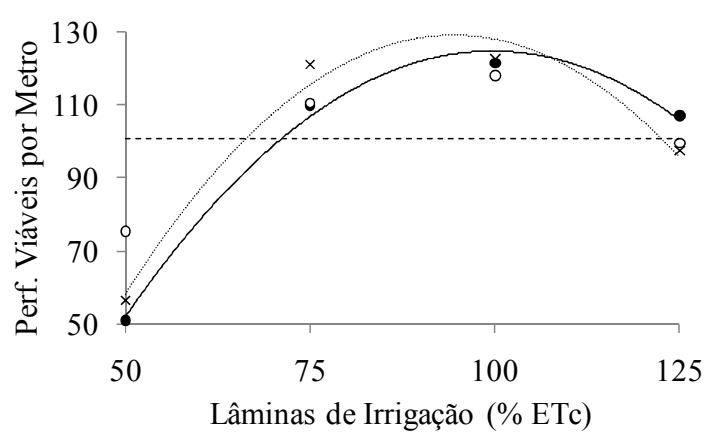

Sampa: PVM $=-167,5750^{*}+5,8630^{* *} \mathrm{LI}-0,0294^{* *} \mathrm{LI}^{2}$ $p<0,0001 \quad \mathrm{R}^{2}=0,9923$

Manduri: $\mathrm{PVM}=100,8750$

195: PVM $=-190,3250^{*}+6,7630^{* *} \mathrm{LI}-0,0358^{* *} \mathrm{LI}^{2}$ $p=0,0028 \quad \mathrm{R}^{2}=0,9766$

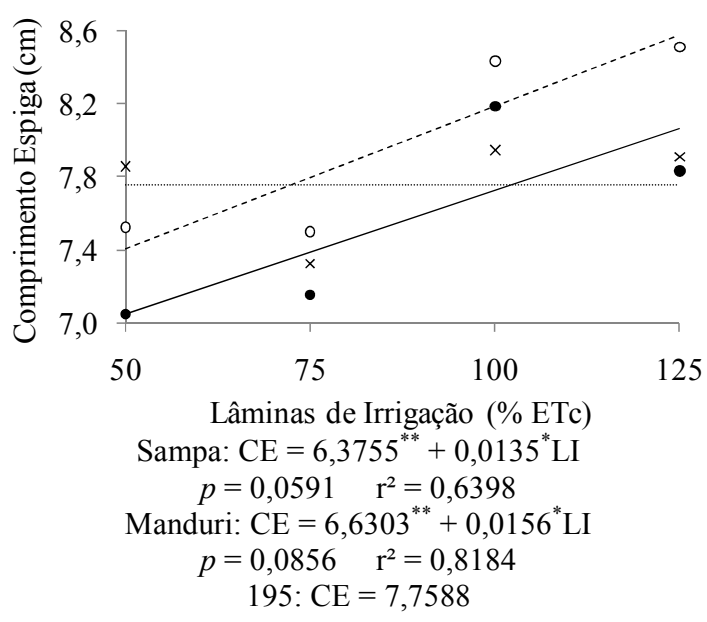


continuação
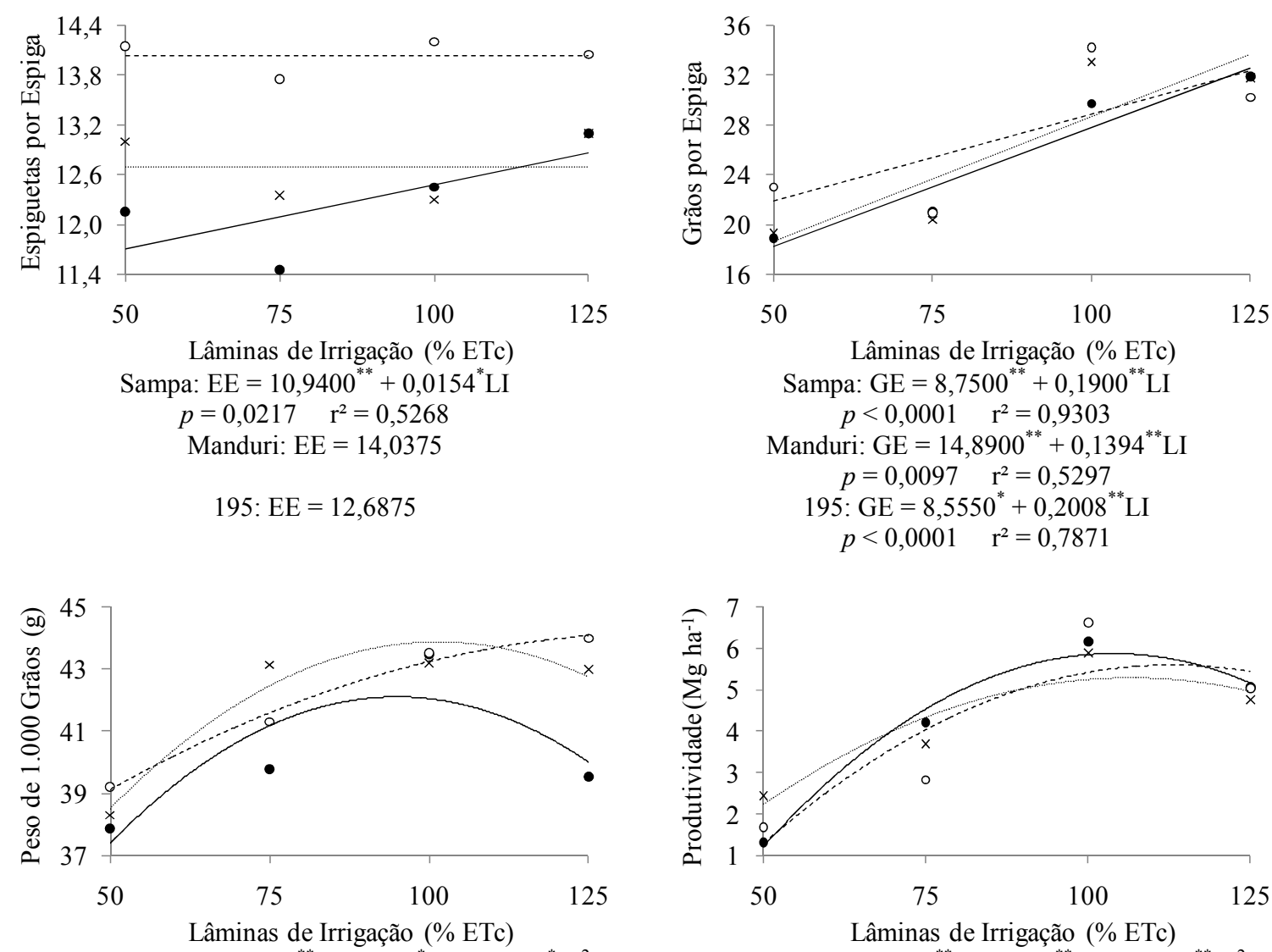

Sampa: PMS $=21,1675^{* *}+0,4408^{*} \mathrm{LI}-0,0023^{*} \mathrm{LI}^{2}$ $p=0,0820 \quad \mathrm{R}^{2}=0,7361$

Manduri: PMS $=31,7712^{* *}+0,1797^{*} \mathrm{LI}-0,0007^{*} \mathrm{LI}^{2}$ $p=0,0139 \quad \mathrm{R}^{2}=0,9871$

195: PMS $=23,0775^{* *}+0,4099^{*} \mathrm{LI}-0,0020^{*} \mathrm{LI}^{2}$ $p=0,0072 \quad \mathrm{R}^{2}=0,9428$

Sampa: $\mathrm{P}=-11,3956^{* *}+0,3322^{* *} \mathrm{LI}-0,0016^{* *} \mathrm{LI}^{2}$ $p<0,0001 \quad \mathrm{R}^{2}=0,9824$

Manduri: $\mathrm{P}=-8,2710^{*}+0,2457^{*} \mathrm{LI}-0,0011^{*} \mathrm{LI}^{2}$ $p=0,0003 \quad \mathrm{R}^{2}=0,7795$ 195: $\mathrm{P}=-5,5349^{*}+0,2030^{* *} \mathrm{LI}-0,0010^{* *} \mathrm{LI}^{2}$ $p=0,0002 \quad \mathrm{R}^{2}=0,8607$
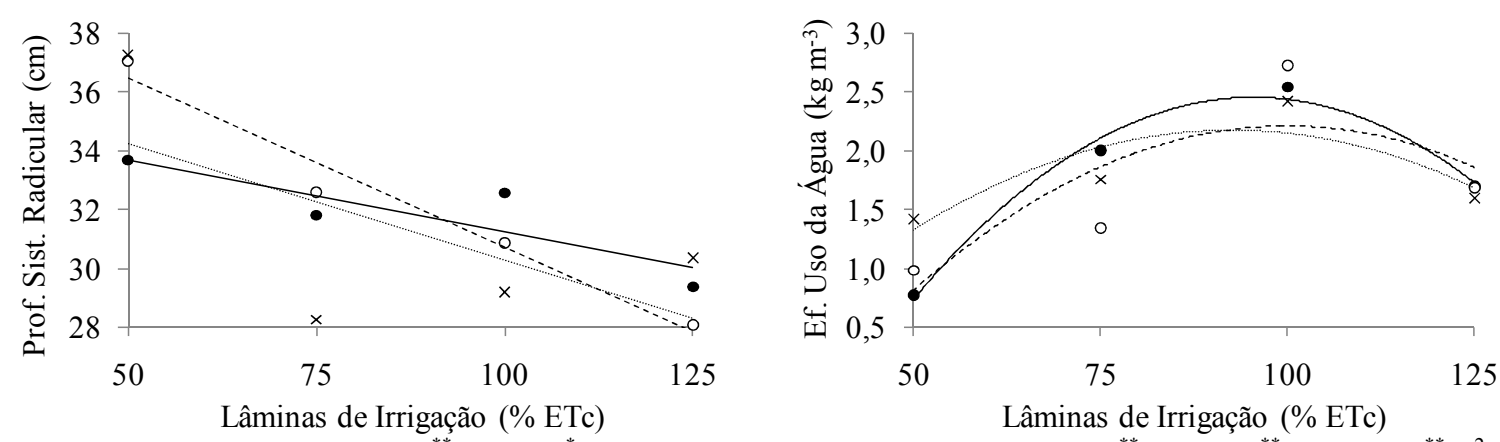
Sampa: PSR $=36,1250^{* *}-0,0488^{*} \mathrm{LI}$ $p=0,0648 \quad \mathrm{r}^{2}=0,7419$ Manduri: PSR $=42,2000^{* *}-0,1149^{* *} \mathrm{LI}$ $p<0,0001 \quad \mathrm{r}^{2}=0,9666$

195: PSR $=38,1563^{* *}-0,0788^{*} \mathrm{LI}$ $p=0,0216 \quad \mathrm{r}^{2}=0,3875$ Sampa: EUA $=-5,1218^{* *}+0,1586^{* *} \mathrm{LI}-0,0008^{* *} \mathrm{LI}^{2}$ $p=0,0003 \quad \mathrm{R}^{2}=0,9850$

Manduri: EUA $=-3,3960^{* *}+0,1121^{*} \mathrm{LI}-0,0006^{* *} \mathrm{LI}^{2}$ $p=0,0053 \quad \mathrm{R}^{2}=0,6500$

195: EUA $=-1,8318^{*}+0,0865^{* *} \mathrm{LI}-0,0005^{* *} \mathrm{LI}^{2}$ $p=0,0147 \quad \mathrm{R}^{2}=0,7105$

$$
\begin{aligned}
& \text { - BRS Sampa } \quad \cdots \text {.-. BRS Manduri } \times \text { BRS } 195 \\
& * * e^{*} \text { significativo a } 1 \text { e } 5 \% \text { de probabilidade, respectivamente. }
\end{aligned}
$$

Fonte: Elaboração dos autores. 
Tabela 2. Valores médios de altura de planta, matéria seca da parte aérea, perfilhos por planta, perfilhos viáveis por metro, perfilhos inviáveis por metro, comprimento de espiga, espiguetas por espiga, grãos por espiga, peso de 1.000 grãos, produtividade de grãos, profundidade do sistema radicular e eficiência do uso da água em função das lâminas de irrigação e cultivares de cevada. Chapadão do Sul-MS, 2012.

\begin{tabular}{|c|c|c|c|c|c|}
\hline \multirow{2}{*}{ Parâmetro } & \multirow{2}{*}{ Cultivar } & \multicolumn{4}{|c|}{ Lâminas de Irrigação (\% ETc) } \\
\hline & & 50 & 75 & 100 & 125 \\
\hline \multirow{3}{*}{$\begin{array}{l}\text { Altura de Planta } \\
\qquad(\mathrm{cm})\end{array}$} & BRS Sampa & $48,02 \mathrm{a}$ & $57,42 \mathrm{a}$ & $64,47 \mathrm{a}$ & $63,64 \mathrm{a}$ \\
\hline & BRS Manduri & $50,06 \mathrm{a}$ & $61,75 \mathrm{a}$ & $65,22 \mathrm{a}$ & $68,13 \mathrm{a}$ \\
\hline & BRS 195 & $49,00 \mathrm{a}$ & $59,81 \mathrm{a}$ & $68,03 \mathrm{a}$ & $68,44 \mathrm{a}$ \\
\hline \multirow{3}{*}{$\begin{array}{c}\text { Matéria Seca da Parte } \\
\text { Aérea } \\
\left(\mathrm{Mg} \mathrm{ha}^{-1}\right) \\
\end{array}$} & BRS Sampa & $56,19 \mathrm{a}$ & $62,89 \mathrm{a}$ & $77,01 \mathrm{a}$ & $71,81 \mathrm{a}$ \\
\hline & BRS Manduri & $52,40 \mathrm{a}$ & $60,60 \mathrm{a}$ & $65,90 \mathrm{a}$ & $88,38 \mathrm{a}$ \\
\hline & BRS 195 & $61,42 \mathrm{a}$ & $78,26 \mathrm{a}$ & $78,04 \mathrm{a}$ & $76,83 \mathrm{a}$ \\
\hline \multirow{3}{*}{ Perfilhos por Planta } & BRS Sampa & $2,03 \mathrm{a}$ & $2,16 \mathrm{a}$ & $3,22 \mathrm{a}$ & $3,69 \mathrm{a}$ \\
\hline & BRS Manduri & $2,28 \mathrm{a}$ & $2,13 \mathrm{a}$ & $2,63 \mathrm{~b}$ & $2,72 \mathrm{~b}$ \\
\hline & BRS 195 & $2,38 \mathrm{a}$ & $2,06 \mathrm{a}$ & $3,28 \mathrm{a}$ & $3,00 \mathrm{~b}$ \\
\hline \multirow{3}{*}{$\begin{array}{l}\text { Perfilhos Viáveis } \\
\text { por Metro }\end{array}$} & BRS Sampa & $51,0 \mathrm{a}$ & $110,0 \mathrm{a}$ & $121,5 \mathrm{a}$ & $107,0 \mathrm{a}$ \\
\hline & BRS Manduri & $75,5 \mathrm{a}$ & $110,5 \mathrm{a}$ & $118,0 \mathrm{a}$ & $99,5 \mathrm{a}$ \\
\hline & BRS 195 & $56,5 \mathrm{a}$ & $121,0 \mathrm{a}$ & $122,5 \mathrm{a}$ & $97,5 \mathrm{a}$ \\
\hline \multirow{3}{*}{$\begin{array}{l}\text { Perfilhos Inviáveis } \\
\text { por Metro }\end{array}$} & BRS Sampa & $29,00 \mathrm{a}$ & $34,00 \mathrm{a}$ & $29,50 \mathrm{a}$ & $29,00 \mathrm{a}$ \\
\hline & BRS Manduri & $24,00 \mathrm{a}$ & $27,00 \mathrm{a}$ & $34,50 \mathrm{a}$ & $26,50 \mathrm{a}$ \\
\hline & BRS 195 & $23,00 \mathrm{a}$ & $31,50 \mathrm{a}$ & $32,50 \mathrm{a}$ & $33,00 \mathrm{a}$ \\
\hline \multirow{3}{*}{$\begin{array}{l}\text { Comprimento } \\
\text { de Espiga } \\
(\mathrm{cm}) \\
\end{array}$} & BRS Sampa & $7,05 \mathrm{a}$ & $7,16 \mathrm{a}$ & $8,19 \mathrm{a}$ & $7,83 \mathrm{a}$ \\
\hline & BRS Manduri & $7,52 \mathrm{a}$ & $7,50 \mathrm{a}$ & $8,44 \mathrm{a}$ & $8,51 \mathrm{a}$ \\
\hline & BRS 195 & $7,86 \mathrm{a}$ & $7,33 \mathrm{a}$ & $7,95 \mathrm{a}$ & $7,91 \mathrm{a}$ \\
\hline \multirow{3}{*}{ Espiguetas por Espiga } & BRS Sampa & $12,15 \mathrm{~b}$ & $11,45 \mathrm{~b}$ & $12,45 \mathrm{~b}$ & $13,10 \mathrm{a}$ \\
\hline & BRS Manduri & $14,15 \mathrm{a}$ & $13,75 \mathrm{a}$ & $14,20 \mathrm{a}$ & $14,05 \mathrm{a}$ \\
\hline & BRS 195 & $13,00 \mathrm{ab}$ & $12,35 \mathrm{ab}$ & $12,30 \mathrm{~b}$ & $13,10 \mathrm{a}$ \\
\hline \multirow{3}{*}{ Grãos por Espigueta } & BRS Sampa & $18,90 \mathrm{a}$ & $21,05 \mathrm{a}$ & $29,70 \mathrm{a}$ & $31,85 \mathrm{a}$ \\
\hline & BRS Manduri & $23,00 \mathrm{a}$ & $20,95 \mathrm{a}$ & $34,20 \mathrm{a}$ & $30,20 \mathrm{a}$ \\
\hline & BRS 195 & $19,30 \mathrm{a}$ & $20,35 \mathrm{a}$ & $33,05 \mathrm{a}$ & $31,80 \mathrm{a}$ \\
\hline \multirow{3}{*}{$\begin{array}{l}\text { Peso de } 1.000 \text { Grãos } \\
(\mathrm{g})\end{array}$} & BRS Sampa & $37,88 \mathrm{a}$ & $39,78 \mathrm{a}$ & $43,45 \mathrm{a}$ & $39,55 \mathrm{a}$ \\
\hline & BRS Manduri & $39,23 \mathrm{a}$ & $41,30 \mathrm{a}$ & $43,53 \mathrm{a}$ & $43,98 \mathrm{a}$ \\
\hline & BRS 195 & $38,30 \mathrm{a}$ & $43,13 \mathrm{a}$ & $43,20 \mathrm{a}$ & $42,98 \mathrm{a}$ \\
\hline \multirow{3}{*}{$\begin{array}{c}\text { Produtividade } \\
\text { de Grãos } \\
\left(\mathrm{Mg} \mathrm{ha}^{-1}\right)\end{array}$} & BRS Sampa & $1,33 \mathrm{a}$ & $4,21 \mathrm{a}$ & $6,17 \mathrm{a}$ & $5,06 \mathrm{a}$ \\
\hline & BRS Manduri & $1,69 \mathrm{a}$ & $2,83 \mathrm{a}$ & $6,62 \mathrm{a}$ & $5,03 \mathrm{a}$ \\
\hline & BRS 195 & $2,45 \mathrm{a}$ & $3,70 \mathrm{a}$ & $5,88 \mathrm{a}$ & $4,75 \mathrm{a}$ \\
\hline \multirow{3}{*}{$\begin{array}{l}\text { Profundidade do Sistema } \\
\text { Radicular } \\
(\mathrm{cm})\end{array}$} & BRS Sampa & $33,69 \mathrm{a}$ & $31,81 \mathrm{ab}$ & $32,56 \mathrm{a}$ & $29,38 \mathrm{a}$ \\
\hline & BRS Manduri & $37,06 \mathrm{a}$ & $32,59 \mathrm{a}$ & $30,88 \mathrm{a}$ & $28,06 \mathrm{a}$ \\
\hline & BRS 195 & $37,25 \mathrm{a}$ & $28,25 \mathrm{~b}$ & $29,19 \mathrm{a}$ & $30,38 \mathrm{a}$ \\
\hline \multirow{3}{*}{$\begin{array}{l}\text { Eficiência do } \\
\text { Uso da Água } \\
\quad\left(\mathrm{kg} \mathrm{m}^{-3}\right)\end{array}$} & BRS Sampa & $0,77 \mathrm{a}$ & $2,00 \mathrm{a}$ & $2,54 \mathrm{a}$ & $1,70 \mathrm{a}$ \\
\hline & BRS Manduri & $0,98 \mathrm{a}$ & $1,34 \mathrm{a}$ & $2,73 \mathrm{a}$ & $1,69 \mathrm{a}$ \\
\hline & BRS 195 & $1,42 \mathrm{a}$ & $1,75 \mathrm{a}$ & $2,43 \mathrm{a}$ & $1,59 \mathrm{a}$ \\
\hline
\end{tabular}

Médias seguidas pela mesma letra na coluna não diferem entre si pelo teste de Tukey $(p<0,05)$.

Fonte: Elaboração dos autores. 
As irrigações não afetaram o número de perfilhos viáveis da cevada BRS Manduri. Para as cultivares BRS Sampa e BRS 195, os valores máximos estimados pela equação de regressão foram de 125 e 129, para as lâminas de irrigação de 99,7 e $94,5 \%$ da ETc, respectivamente (Figura 2). Esse resultado demonstra que essas cultivares de cevada são sensíveis ao déficit hídrico quanto ao número de perfilhos viáveis. Pesquisas mostram que esse resultado também acontece em outros cereais. Waraich et al. (2008) e Akhkha, Boutraa e Alhejely (2011) trabalhando com a cultura do trigo também observaram que o déficit hídrico favorece um menor número de perfilhos viáveis.

O número de perfilhos inviáveis não foi afetado pelas diferentes cultivares de cevada (Tabela 1 e 2) e lâminas de irrigação (Figura 2). A planta de cevada é hospedeira de doenças fúngicas, principalmente do oídio (Blumeria graminis f.sp. tritici), que proporciona perfilhos inviáveis e que não apresentam espigas formadas. A incidência de oídio em cevada é favorecida em temperatura ótima de $20{ }^{\circ} \mathrm{C}$ e quando há baixa umidade do ar (THORDAL-CHRISTENSEN et al., 2001).

As diferentes cultivares de cevada não afetaram o comprimento de espiga (Tabela 1). O comprimento entre todos os tratamentos variou entre 7,05 e 8,51 cm (Tabela 2) e corrobora com Monteiro (2012), que encontrou valores variando entre 4,0 e 10,3 cm. As diferentes lâminas de irrigação não afetaram o comprimento de espiga da cultivar BRS 195, entretanto, esse parâmetro respondeu as diferentes lâminas de irrigação para os outros materiais, onde foi observado efeito linear positivo (Figura 2). Esse efeito é importante, pois associado a outros fatores, o comprimento de espiga irá determinar o potencial de produtividade de grãos de cevada.

A cultivar BRS Manduri apresentou maior número de espiguetas por espiga em relação a BRS Sampa nos tratamentos com lâminas de irrigação de 50, 75 e 100\% da ETc. A BRS 195 não diferiu das demais cultivares nas lâminas de irrigação de 50 e $75 \%$ da ETc e apresentou menor número de espiguetas por espiga que a BRS Sampa no tratamento que teve $100 \%$ da ETc reposta. Na lâmina de irrigação de $125 \%$ da ETc, as cultivares não diferiram entre si (Tabela 2). As cultivares BRS Manduri e BRS 195 não foram afetadas pelas lâminas de irrigação (Figura 2). A ausência de resposta desse parâmetro à irrigação era esperada, pois essa característica é de alta herdabilidade e menos dependente do ambiente (FERREIRA et al., 2011). Para a cultivar BRS Sampa, observou-se efeito linear positivo (Figura 2), ou seja, o aumento da lâmina de irrigação proporcionou aumento no número de espiguetas por espiga.

Não foi verificado efeito da cultivar de cevada no número de grãos por espiga (Tabela 1). Esse parâmetro juntamente com o número de espiguetas por espiga e comprimento de espiga são os mais importantes para determinação do potencial de produtividade de grãos da cevada. As diferentes lâminas de irrigação proporcionaram efeito linear positivo no número de grãos por espiga (Figura 2). Esse resultado corrobora com os obtidos por Guerra (1994) e Mollah e Paul (2011), entretanto, segundo Ferreira et al. (2011), o maior efeito do estresse hídrico está relacionado à formação do grão (peso de mil grãos), e não ao número de grãos. Diante disso, a disponibilidade hídrica afetará apenas o processo de enchimento dos grãos, que também será importante para determinar o potencial produtivo da cevada. Já Santos et al. (2012) relatam que a fase pré-antese pode ser afetada pelo estresse hídrico, com consequente queda do número de grãos por espiga. Esse resultado pode ser creditado na redução na área foliar, em virtude da redução do número e tamanho de folhas, produzindo menores taxas fotossintéticas por unidade de área. Esse fato possivelmente aconteceu no presente experimento, uma vez que na fase de formação da espiga, havia pouca chuva (Figura 1) e a disponibilidade hídrica foi realizada de acordo com os tratamentos.

O peso de 1.000 grãos não foi afetado pelas diferentes cultivares (Tabela 1), e seus valores em todos os tratamentos variaram entre 37,9 e 44,0 
g (Tabela 2). Esses valores ficaram próximo aos encontrados por Guerra (1994) que apresenta valores compreendidos entre 42,4 e 43,1 g; Mollah e Paul (2011) entre 36,0 e 38,2 g; Borowski (2012) entre 42,1 e 45,9 g; e Monteiro (2012) entre 38,7 e 39,2 g. As diferentes lâminas de irrigação proporcionaram efeito quadrático no peso de 1.000 grãos das diferentes cultivares de cevada (Figura 2). Os valores máximos de peso de 1.000 grãos, estimados pelas equações de regressão, para as cultivares BRS Sampa, BRS Manduri e BRS 195 foram de 42,3; 43,3 e 44,1 g, para as lâminas de irrigação de 95,8; 128,4 e $102,5 \%$ da ETc, respectivamente. Guerra (1994) também verificou em seu trabalho efeito da disponibilidade hídrica nesse parâmetro. O peso de 1.000 grãos, segundo Monteiro (2012), é altamente dependente do clima, principalmente em relação à disponibilidade de água pelas chuvas. Jalata, Ayana e Zeleke (2011) em trabalho realizado na Etiópia, também verificaram que essa característica é altamente dependente do ambiente.

A produtividade de grãos de cevada não diferiu entre as cultivares testadas (Tabela 1). Apesar das cultivares apresentarem valores diferentes de espiguetas por espiga, houve uma compensação dos outros fatores (comprimento e número de grãos por espiga), para dessa forma, resultar em produtividade de grãos que não diferisse estatisticamente. Já as lâminas de irrigação proporcionaram efeito quadrático na produtividade de grãos das cultivares de cevada (Figura 2) corroborando com Guerra (1994) e Mollah e Paul (2011). As produtividades máximas de grãos, estimadas pela equação de regressão, para as cultivares BRS Sampa, BRS Manduri e BRS 195 foram de 5.848, 5.449 e 4.767 $\mathrm{kg} \mathrm{ha}^{-1}$, para as lâminas de irrigação de 103,8; 111,7 e $101,5 \%$ da ETc, respectivamente. A produtividade média das cultivares BRS Sampa, BRS Manduri e BRS 195, segundo a EMBRAPA (2013), são 5.000, 7.000 e $6.000 \mathrm{~kg} \mathrm{ha}^{-1}$, respectivamente. Observa-se que a cultivar BRS Sampa apresentou valor 17\% superior em relação a produtividade divulgada pelo detentor. É oportuno ressaltar que BRS Sampa é o único material existente recomendado para o Estado de São Paulo, e pelos resultados, também poderá ser utilizado em região de cerrado de altitude, como na região nordeste do Estado de Mato Grosso do Sul. Além do mais, o experimento foi conduzido apenas em uma safra, o que torna mais seguro a recomendação da cultivar BRS Sampa. As demais cultivares apresentaram desempenhos satisfatórios, entretanto, pesquisas adicionais deverão ser realizadas para atestá-las. As produtividades de grãos da BRS Manduri e BRS 195, materiais recomendados para a região Sul do País, foram 21\% inferiores a produtividade divulgada pelo detentor. Acredita-se que essas produtividades de grãos de cevada foram alcançadas devido às baixas temperaturas durante o período experimental, em que as temperaturas médias ficaram em torno de $20{ }^{\circ} \mathrm{C}$ e as máximas não passaram de $30^{\circ} \mathrm{C}$ (Figura 1A).

No tratamento com lâmina de irrigação de $75 \%$ da ETc, a cevada BRS Manduri apresentou maior profundidade do sistema radicular em relação a BRS 195. Nas demais lâminas de irrigação não foram verificadas diferença significativa (Tabela 2). Independente da cultivar, as lâminas de irrigação proporcionaram efeito linear negativo na profundidade do sistema radicular, ou seja, o aumento da lâmina de irrigação proporcionou redução na profundidade das raízes (Figura 2). Esse resultado, possivelmente, foi devido a cevada nos tratamentos com menores lâminas de irrigação ter sofrido com o estresse hídrico, e como forma de defesa, aprofundou seu sistema radicular para succionar água em maiores profundidades. Já nos tratamentos que não houve estresse hídrico, com lâminas de irrigação com 100 e $125 \%$ da ETc, as raízes não necessitaram de aprofundar para retirar essa água. Segundo Alencar et al. (2010), existem algumas desvantagem das raízes não aprofundarem no solo. Sistemas radiculares superficiais ou rasos são mais propensos ao acamamento, sofrem rapidamente estresse hídrico com a falta de chuva ou irrigação e reduzem o raio de ação para obtenção de nutrientes no solo. 
A eficiência de uso da água pela cevada não diferiu entre as cultivares testadas (Tabela 1). O maior valor de eficiência de uso da água, em todos os tratamentos, foi $2,73 \mathrm{~kg} \mathrm{~m}^{-3}$, ou seja, para produção de $1.000 \mathrm{~kg}$ de grãos de cevada foram necessários 366.000 litros de água. Já as lâminas de irrigação proporcionaram efeito quadrático na eficiência de uso da água pela cevada (Figura 2) corroborando com Guerra (1994), Araya et al. (2010) e Mollah e Paul (2011). As máximas eficiências de uso da água pela cevada, estimadas pela equação de regressão, para as cultivares BRS Sampa, BRS Manduri e BRS 195 foram de 2,74; 1,84 e 1,91 $\mathrm{kg} \mathrm{m}^{-3}$, para as lâminas de irrigação de 99,1; 93,4 e 86,5\% da ETc, respectivamente. A produção de grãos de cevada é função de outros fatores além do consumo de água, como a fertilidade do solo, que pode influenciar consideravelmente nos valores de produtividade de grãos e consequentemente influenciarem os valores de eficiência de uso da água. Waraich et al. (2008) ao analisarem diferentes cultivares de trigo sob diferentes regimes hídricos, concluíram que o aumento da lâmina de irrigação também pode implicar em uma menor eficiência de uso da água.

Em geral, observou-se que as características agronômicas importantes da cultura da cevada (perfilhos viáveis, peso de 1.000 grãos, produtividade e eficiência do uso da água) apresentaram desempenhos máximos quando a cultura foi irrigada com reposição próxima de $100 \%$ da ETc. Diante disso, recomenda-se que a cevada cervejeira seja irrigada com reposição total de sua evapotranspiração, no cerrado sul-mato-grossense.

\section{Conclusões}

As características agronômicas da cevada não foram afetadas pelas cultivares de cevada, entretanto, recomenda-se para o nordeste sul-matogrossense a BRS Sampa, que foi desenvolvida para uma região de clima semelhante. A irrigação é fundamental para a produção de cevada cervejeira na região e recomenda-se o manejo com reposição de $100 \%$ da evapotranspiração da cultura.

\section{Agradecimentos}

À EMBRAPA Trigo pela disponibilização das sementes, à Petroisa Irrigação pela doação do sistema de irrigação e ao Grupo Feltre pela doação de cápsulas tensiométricas para aferição do manejo da irrigação.

\section{Referências}

AKHKHA, A.; BOUTRAA, T.; ALHEJELY, A. The rates of photosynthesis, chlorophyll content, dark respiration, proline and abscicic acid (ABA) in wheat (Triticum durum) under water deficit conditions. International Journal of Agriculture e Biology, Faisalabad, v. 13, n. 2, p. 215-221, 2011.

ALENCAR, C. A. B.; OLIVEIRA, R. A.; CÓSER, A. C.; MARTINS, C. E.; CUNHA, F. F. Comportamento do sistema radicular de capins manejados por pastejo submetidos a diferentes lâminas de irrigação. Engenharia na Agricultura, Viçosa, v. 18, n. 5, p. 429-437, 2010.

AMABILE, R. A.; MINELlA, E.; GUERRA, A. F.; SILVA, D. B.; ALBRECHT, J. C.; ANTONIAZZI, N. BRS Deméter: nova cultivar de cevada cervejeira irrigada para o Cerrado do Brasil Central. Pesquisa Agropecuária Brasileira, Brasília, v. 43, n. 9, p. 1247-1249, 2008.

ARAYA, A.; HABTU, S.; HADGU, K. M.; KEBEDE, A.; DEJENE, T. Test of AquaCrop model in simulating biomass and yield of water deficient and irrigated barley (Hordeum vulgare). Agricultural Water Management, New York, v. 97, n. 11, p. 1838-1846, 2010.

BOROWSKI, D. Z. Efeito do genótipo, ambiente e suas interações em características agronômicas e de qualidade em cevada cervejeira no sul do Brasil. 2012. Dissertação (Mestrado em Agronomia) - Universidade de Passo Fundo, Passo Fundo.

COSTA, M. H. Análise de dados de precipitação. Viçosa: AEAMG, 1994. 21 p. (Caderno didático, 11).

DENÍCULI, W.; BERNARDO, S.; THIÁBAUT, J. T. L.; SEDIYAMA, G. C. Uniformidade de distribuição de água, em condições de campo num sistema de irrigação por gotejamento. Revista Ceres, Viçosa, v. 27, n. 50, p. 155-162, 1980.

EMPRESA BRASILEIRA DE PESQUISA AGROPECUÁRIA - EMBRAPA. Cultivares de cevada. Passo Fundo: EMBRAPA, 2013. Disponível em: $<$ http:// www.cnpt.embrapa.br/culturas/cevada/cultivares/ cultivares_recomendadas.htm>. Acesso em: 31 jan. 2013. 
FERREIRA, M. A. F.; BRITO, M. E. B.; COSTA, F. B.; ARAÚJO FILHO, G. D.; ALVINO, F. C. G. Aspectos químicos e físicos dos grãos de milho doce sob estresse hídrico. Revista Brasileira de Agrotecnologia, Pombal, v. 1, n. 1, p. 1-6, 2011.

GUERRA, A. F. Manejo de irrigação da cevada sob condições de cerrado visando o potencial de produção. Pesquisa Agropecuária Brasileira, Brasília, v. 29, n. 7, p. 1111-1118, 1994.

GUERRA, A. F.; ROCHA, O. C. Método do tanque classe A para irrigação da cevada, cultivar BRS 195, no cerrado. Planaltina: Embrapa Cerrados, 2004. 2 p. (EMBRAPA Cerrados. Comunicado técnico, 115).

JALATA, Z.; AYANA, A.; ZELEKE, H. Variability, heritability and genetic advance for some yield and yield related traits in Ethiopian barley (Hordeum vulgare L.) landraces and crosses. International Journal of Plant Breeding and Genetics, New York, v. 5, n. 1, p. 44-52, 2011.

KELLER, J.; KARMELI, D. Trickle irrigation design. Glendora: Rain Bird Sprinkler Manufacturing, 1975. 133 p.

MINELLA, E. Adubação da cevada. 2012. Disponível em: $\quad<\mathrm{http} / / /$ sistemasdeproducao.cnptia.embrapa.br/ FontesHTML/Cevada/CultivodeCevada_4ed/calagem. htm>. Acesso em: 10 abr. 2012.

MOLLAH, M. S. I.; PAUL, N. K. Responses of irrigation and fertilizers on the growth and yield of Hordeum vulgare L. Bangladesh Journal of Scientific and Industrial Research, Bangladesh, v. 46, n. 3, p. 369-374, 2011.

MONTEIRO, V. A. Diversidade genética de acessos de cevada sob sistema de produção irrigado no Cerrado do Planalto Central brasileiro. 2012. Dissertação (Mestrado em Agronomia) - Universidade de Brasília, Brasília.
PIETERSE, P. A.; RETHMAN, N. F. G.; VAN BOCH, J. Production, water use efficiency and quality of four cultivars of Panicum maximum Jacq. at different levels of nitrogen fertilization. Tropical Grassland, Brisbane, v. 31, n. 2, p. 117-123, 1997.

PREFEITURA MUNICIPAL CHAPADÃO DO SUL. Situação geográfica. 2012. Disponível em: <http://www. chapadaodosul.ms.gov.br>. Acesso em: 18 out. 2014.

RAHMAN, M. S.; SARKER, A. M.; ISLAM, M. S.; PAUL, N. K. Effect of soil moisture on grain yield of wheat (Triticum aestivum L. ) cultivars. Environment e Ecology, New Delhi, v. 19, n. 2, p. 304-308, 2001.

RICHARDS, L. A. Methods of measuring soil moisture tension. Soil Science of American Journal, Baltimore, v. 68, n. 1, p. 95-112, 1949.

SANTOS, D.; GUIMARÃES, V. F.; KLEIN, J.; FIOREZE, S. L.; MACEDO JÚNIOR, E. K. Cultivares de trigo submetidas a déficit hídrico no início do florescimento, em casa de vegetação. Revista Brasileira de Engenharia Agrícola Ambiental, Campina Grande, v. 16, n. 8, p. 836-842, 2012.

THORDAL-CHRISTENSEN, H.; GREGERSEN, P. L.; COLLINGE, D. B. The barley/Blumeria (syn. Erysiphe) graminis interaction. In: SLUSARENKO, A. J.; FRASER, R. S. S.; VAN LOON, L. C. Mechanisms of resistance to plant diseases. The Netherlands: Kluwer Academic Publishers, 2001. p. 77-100.

WARAICH, E. A.; AHMAD, R.; AHMAD, S.; ULLAH, $S$. Water use efficiency and yield performance of wheat (Triticum aestivum L.) under different levels of irrigation and nitrogen. Revista Caderno de Pesquisa, Santa Cruz do Sul, v. 20, n. 1, p. 23-35, 2008.

YALÇIN, E.; ÇELIK, S.; AKAR, T.; SAYIM, I.; KÖKSEL, H. Effects of genotype and environment on b-glucan and dietary fiber contents of hull-less barley grown in Turkey. Food Chemistry, London, v. 101, n. 1, p. 171-176, 2007. 